\title{
Combinatorial drug design targeting multiple cancer signaling networks controlled by mitochondrial Hsp90
}

\author{
Byoung Heon Kang, ${ }^{1}$ Janet Plescia, ${ }^{1}$ Ho Young Song, ${ }^{2}$ Massimiliano Meli, ${ }^{3}$ Giorgio Colombo, ${ }^{3}$ \\ Kristin Beebe, ${ }^{4}$ Bradley Scroggins, ${ }^{4}$ Len Neckers, ${ }^{4}$ and Dario C. Altieri ${ }^{1}$ \\ 1 University of Massachusetts Medical School, Worcester, Massachusetts, USA. ${ }^{2}$ LegoChem Biosciences Inc., Daejeon, Republic of Korea. \\ ${ }^{3}$ Istituto di Chimica del Riconoscimento Molecolare, Milan, Italy. ${ }^{4}$ Center for Cancer Research, National Cancer Institute, Bethesda, Maryland, USA.
}

\begin{abstract}
Although therapeutically targeting a single signaling pathway that drives tumor development and/or progression has been effective for a number of cancers, in many cases this approach has not been successful. Targeting networks of signaling pathways, instead of isolated pathways, may overcome this problem, which is probably due to the extreme heterogeneity of human tumors. However, the possibility that such networks may be spatially arranged in specialized subcellular compartments is not often considered in pathway-oriented drug discovery and may influence the design of new agents. Hsp90 is a chaperone protein that controls the folding of proteins in multiple signaling networks that drive tumor development and progression. Here, we report the synthesis and properties of Gamitrinibs, a class of small molecules designed to selectively target $\mathrm{Hsp} 90$ in human tumor mitochondria. Gamitrinibs were shown to accumulate in the mitochondria of human tumor cell lines and to inhibit $\mathrm{Hsp90}$ activity by acting as ATPase antagonists. Unlike $\mathrm{Hsp90}$ antagonists not targeted to mitochondria, Gamitrinibs exhibited a "mitochondriotoxic" mechanism of action, causing rapid tumor cell death and inhibiting the growth of xenografted human tumor cell lines in mice. Importantly, Gamitrinibs were not toxic to normal cells or tissues and did not affect $\mathrm{Hsp} 90$ homeostasis in cellular compartments other than mitochondria. Therefore, combinatorial drug design, whereby inhibitors of signaling networks are targeted to specific subcellular compartments, may generate effective anticancer drugs with novel mechanisms of action.
\end{abstract}

\section{Introduction}

Backed by an unprecedented knowledge of cancer genes (1), it is now possible to disable signaling mechanisms of tumor cells without affecting normal tissues using targeted therapy $(2,3)$. As pioneered by the development of a small molecule antagonist of the BCR-ABL kinase, i.e., imatinib mesylate, targeted cancer therapy is feasible (2), and has produced, in some cases, spectacular clinical responses (4). However, the underlying concept of target-centric drug discovery based on high-throughput screening of potential druggable molecules has been difficult to generalize. Costly, laborintensive, and low-yield (typically one in a million hits reaches the market) (5) target-centric drug discovery has generated many hopeful agents that provided minimal or no gains when tested in the clinic $(6,7)$. This high rate of failure may be due to the extreme heterogeneity of even seemingly identical tumors, carrying hundreds of mutated, amplified, or deregulated genes $(8,9)$. Such complexity makes it difficult to identify a single, driving, signaling pathway suitable for therapeutic intervention, and raises concerns that an imatinib-like approach to drug discovery (4) may be feasible only in a handful of tumors (6).

To overcome these barriers, efforts have begun to explore systems biology tools (10) to model cancer pathways as globally interconnected networks (11). Such connectivity maps, linking together

Conflict of interest: The authors have declared that no conflict of interest exists. Nonstandard abbreviations used: 17-AAG, 17-(allylamino)-17-demethoxygeldanamycin; CsA, cyclosporine A; CypD, cyclophilin D; GA, geldanamycin; Gamitrinib, GA mitochondrial matrix inhibitor; Gamitrinib-G1, Gamitrinib plus 1 tandem repeat of cyclic guanidinium; Gamitrinib-TPP-OH, Gamitrinib plus TPP-OH; TPP-OH, triphenylphosphonium.

Citation for this article: J. Clin. Invest. 119:454-464 (2009). doi:10.1172/JCI37613. multiple signaling pathways (12), may more faithfully recapitulate the tumor tactics responsible for treatment failure, including redundancy, buffering, and modularity into semiautonomous subnetworks (6). This information can also be exploited for a novel pathway-oriented drug discovery (11), with the goal of identifying inhibitors of nodal proteins (5), i.e., molecules that integrate multiple signaling subnetworks $(6,11)$. The expectation is that such network inhibitors may be best suited to simultaneously disable multiple mechanisms of tumor maintenance instead of a single gene and thus overcome the genetic and molecular heterogeneity of progressive disease. The molecular chaperone Hsp90 is a cancer nodal protein (13) and a potentially ideal candidate for pathwayoriented drug discovery (14). In concert with other chaperones, Hsp90 oversees fundamental mechanisms of protein folding quality control via sequential ATPase cycles (15). A distinctive feature of this pathway is its compartmentalization in multiple, semiautonomous, subcellular networks. Accordingly, Hsp90-directed folding controls the stability of hosts of client proteins in the cytosol (15, 16), disassembles transcriptional complexes in the nucleus (17), regulates the early secretory pathway in the endoplasmic reticulum (18), and mediates cell motility in the extracellular milieu (19). Recent studies have expanded this paradigm to another subcellular compartment, the mitochondrion, in which Hsp90 and its related chaperone, TRAP-1 (20), bind components of a permeability transition pore, notably cyclophilin D (CypD) (21), and antagonize its opening, preserving organelle integrity and suppressing the initiation of cell death (22).

To drug the Hsp90 networks in cancer (23), several small molecule ATPase antagonists have been developed from the ansamycin antibiotic geldanamycin $(\mathrm{GA})(14,24)$ or, more recently, from 
A

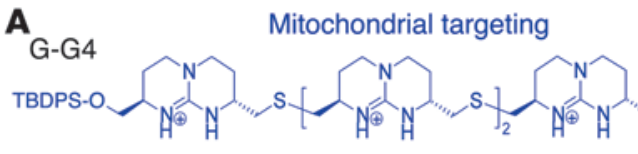

1
$\vdots$

G-G3 1
$\vdots$
1

G-G2

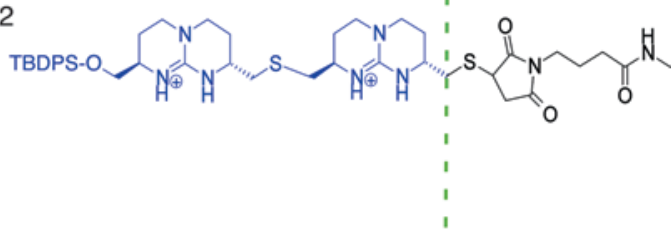

G-G1 :
B
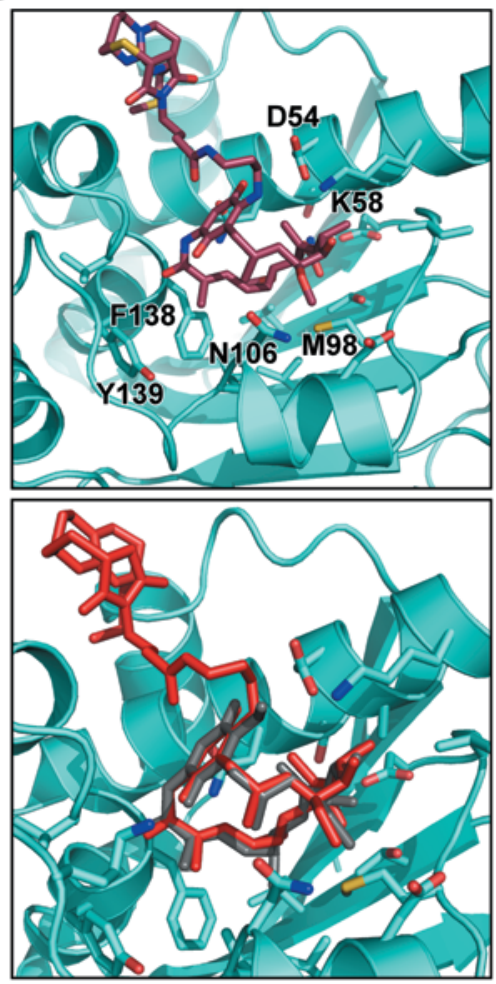

Figure 1

Structure of Gamitrinibs. (A) Combinatorial modular design. The indicated individual modules of Gamitrinibs (mitochondrial targeting, linker, and Hsp90 inhibition) are indicated. G-G1, Gamitrinib-G1; G-TPP, Gamitrinib-TPP-OH; TBDPS, tert-butyldiphenylsilyl. (B) A 3D docking model of Gamitrinib-G1 with Hsp90 N-domain (top panel). The side chains of contact sites are labeled and in color. An overlay of Gamitrinib-G1 (red) and GA (gray) in the ATPase pocket of Hsp90 (bottom panel).

purine or resorcinol structures (25). Backed by encouraging preclinical studies, showing differential activity in tumor cells compared with normal tissues, Hsp90-based therapy has now reached the clinic. However, despite the expectation that these agents may function as genuine pathway inhibitors, their activity in cancer patients has been modest or not observed at all (26).

In this study, we tested the impact of network subcellular compartmentalization in dictating the activity of Hsp90 inhibitors. We report the design of Gamitrinibs (GA mitochondrial matrix inhibitors), which are, to our knowledge, the first class of fully synthetic, combinatorial small molecules, targeting the Hsp90 network in tumor mitochondria (22).

\section{Results}

Selective targeting of the mitochondrial Hsp90 network. We began this study by designing what we believe to be a new class of small molecule Hsp90 antagonists selectively targeted to mitochondria, i.e.,
Gamitrinibs. The chemical synthesis of Gamitrinib is described in detail in the Supplemental Data and Supplemental Figure 1 (supplemental material available online with this article; doi:10.1172/ JCI37613DS1). The structure of Gamitrinib is combinatorial (Figure 1A) and contains a benzoquinone ansamycin backbone derived from the Hsp90 inhibitor 17-(allylamino)-17-demethoxygeldanamycin (17-AAG) (14), a linker region on the C17 position, and a mitochondrial targeting moiety, either provided by 1 to 4 tandem repeats of cyclic guanidinium (27) (Gamitrinib-G1-G4) or triphenylphosphonium (28) (Gamitrinib-TPP-OH) (Figure 1A). By molecular dynamics simulation, the 17-AAG portion of Gamitrinib is predicted to make contacts with the Hsp90 ATPase pocket, whereas the mitochondriotropic guanidinium module is excluded from the binding interface, pointing outside of the ATPase pocket toward the solvent (Figure 1B, top panel). In the predicted docking structure, the binding arrangement of Gamitrinibs to Hsp90 closely follows that of GA (29), with root mean 

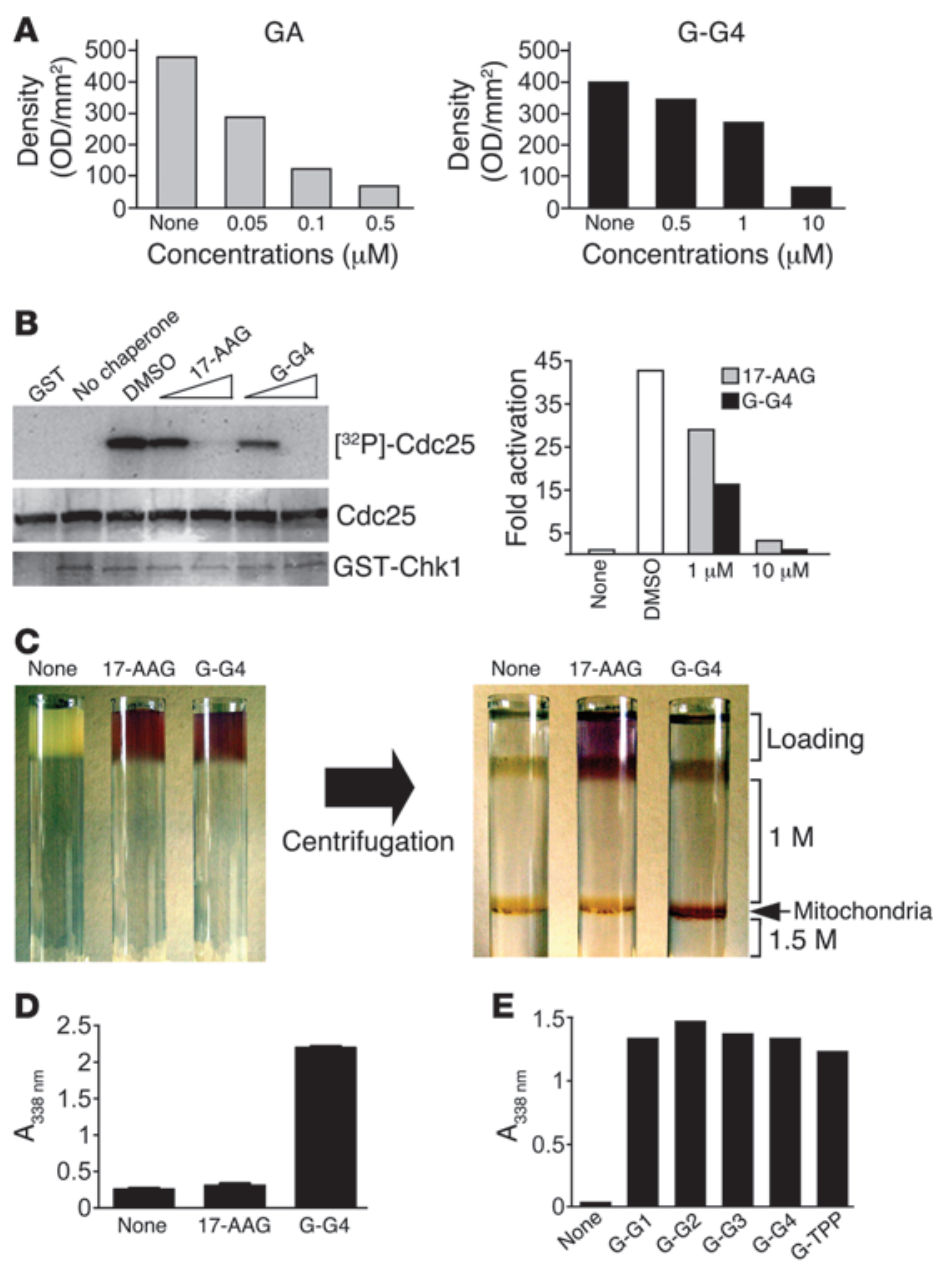

square deviation of heavy atoms of the $17-\mathrm{AAG}$ region being $0.5 \AA$ (Figure 1B, bottom panel).

We next carried out 2 experiments to test whether the addition of a mitochondriotropic moiety reduced the ability of the 17-AAG backbone to bind $\mathrm{Hsp} 90$ and block its chaperone function. In previous studies, modifications of the $\mathrm{C} 17$ position of GA or 17-AAG did not affect inhibition of the chaperone ATPase cycles. Consistent with this, increasing concentrations of GA effectively competed with GA affinity beads for binding to Hsp90 in a tumor cell lysate (Figure 2A, left panel). Similarly, Gamitrinib-G4 displaced Hsp90 from GA affinity beads, albeit less efficiently than $\mathrm{GA}$ in this assay (Figure 2A, right panel). Conversely, increasing concentrations of both unconjugated 17-AAG and Gamitrinib-G4 capably inhibited Hsp90 chaperone activity (Figure 2B), using a purified client protein assay, i.e., Chk1 reconstitution assay (30). We next asked whether the combinatorial design of Gamitrinibs allowed their accumulation in isolated tumor mitochondria. For these experiments, we used a spectrophotometric approach coupled to gradient density ultracentrifugation of cellular extracts for isolation of purified mitochondria (Figure 2C). In preliminary studies, we found that at a drug concentration of $0.2 \mathrm{M}$, unconjugated 17-AAG exhibited 2 peaks of absorption at $338 \mathrm{~nm}$ (absorption, 2.448) and $533 \mathrm{~nm}$ (absorption, 0.182), whereas peak absorption for Gamitrinib-G4 was at $338 \mathrm{~nm}$ (absorption, 2.124) and $543 \mathrm{~nm}$ (absorption, 0.138), respectively. Thus, an absorbance

\section{Figure 2}

Inhibition of Hsp90 chaperone activity. (A) Competition with GA affinity beads. GA (left panel) or Gamitrinib-G4 (right panel), at the indicated concentrations, were incubated with aliquots of SKBr3 tumor cell lysates followed by affinity purification of Hsp90 using GA affinity beads. Data are densitometric quantifications of scanning and image analysis of Hsp90 bands visualized by Western blotting. (B) Inhibition of Chk1 kinase activity. 17-AAG or Gamitrinib-G4 (1-10 $\mu \mathrm{M})$ were analyzed for modulation of Chk1-dependent phosphorylation of Cdc25. Densitometric quantification of protein bands (right panel). (A and B) Data are representative of 2 independent experiments with identical results. (C) Accumulation of Gamitrinib in mitochondria. Cellular extracts were loaded with vehicle (None), unconjugated 17-AAG, or Gamitrinib-G4 and analyzed before (left panel) or after gradient density ultracentrifugation (right panel). The position of the 1-1.5 M interface corresponding to isolated mitochondria is indicated. (D) Quantification of mitochondrial accumulation. Mitochondria isolated from HeLa cells were incubated with 17-AAG, Gamitrinib-G4, or vehicle and analyzed using absorbance. Data are the mean $\pm \operatorname{SEM}(n=3)$. (E) Mitochondriotropic properties of all Gamitrinibs. Mitochondria isolated from Raji cells were incubated with the indicated Gamitrinibs or vehicle and analyzed by absorbance. Data are from a representative experiment out of 2 independent determinations.

at $338 \mathrm{~nm}$ was chosen for all subsequent detection studies of Gamitrinibs. Using these experimental conditions, Gamitrinib-G4 was readily detected at a $1-1.5 \mathrm{M}$ interface, corresponding to isolated mitochondria after gradient density ultracentrifugation (Figure 2, C and D). In contrast, 17-AAG did not localize to the mitochondrial interface as compared with untreated samples (Figure 2, C and D) in agreement with previous observations (22). Using a similar approach, all Gamitrinibs accumulated comparably in isolated tumor mitochondria, regardless of the structure or composition of their mitochondriotropic moieties (Figure 2E).

Gamitrinibs induce sudden mitochondrial permeability transition. When added to isolated tumor mitochondria, Gamitrinibs caused immediate loss of inner mitochondrial membrane potential, all with comparable efficiency, regardless of their different mitochondriotropic moieties (Figure 3A). In contrast, unconjugated Hsp90 inhibitors, including GA, 17-AAG, or 17-(dimethylaminoethylamino)-17-demethoxygeldanamycin (DMAG), did not affect mitochondrial membrane potential (Figure 3A). Next, we asked whether this response was specific for inhibition of Hsp90 chaperone activity inside mitochondria. Consistent with the data presented above, Gamitrinibs (Gamitrinib-G4 or -TPP-OH) suddenly depolarized tumor mitochondria, and this reaction was partially reversed by cyclosporine A (CsA), an inhibitor of the immunophilin CypD (Figure 3B). In contrast, treatment of tumor mitochondria with the mitochondriotropic moieties of Gamitrinbs, tetraguanidinium (TG-OH) or TPP-OH plus unconjugated 17-AAG or GA had no effect on mitochondrial membrane potential, with or without CsA (Figure 3B).

Loss of mitochondrial membrane potential followed by rupture of the outer membrane and release of cytochrome $c$ are hallmarks of mitochondrial permeability transition (21) and the molecular prerequisites for the initiation of the intrinsic pathway of apoptosis (21). To further test this model, we examined the ability of Gamitrinibs to induce cytochrome $c$ release from isolated tumor 
A

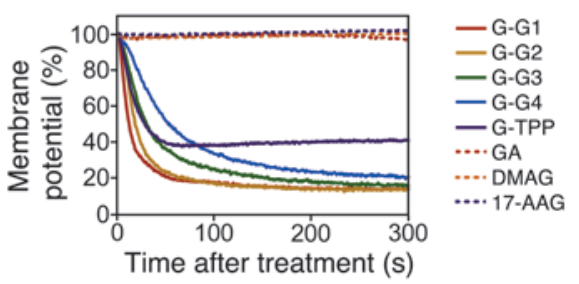

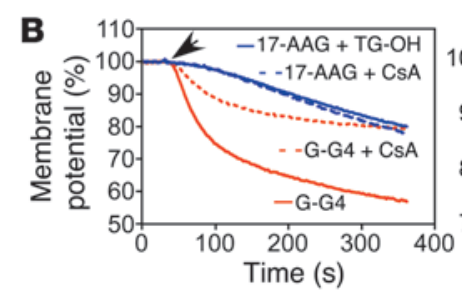

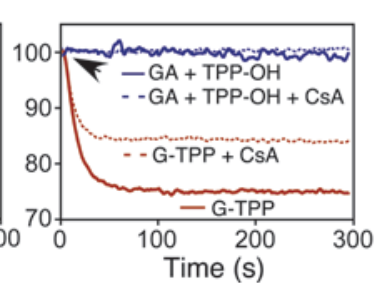

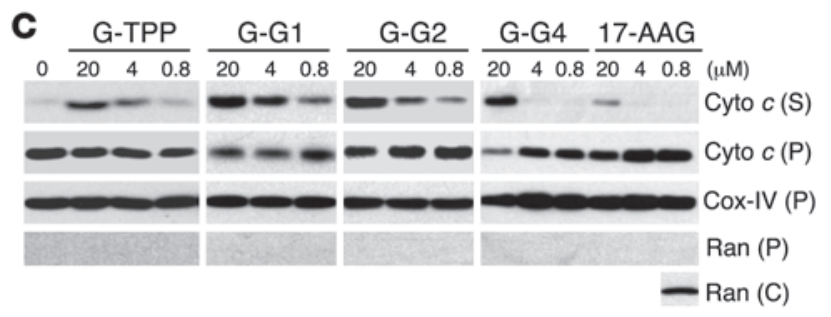
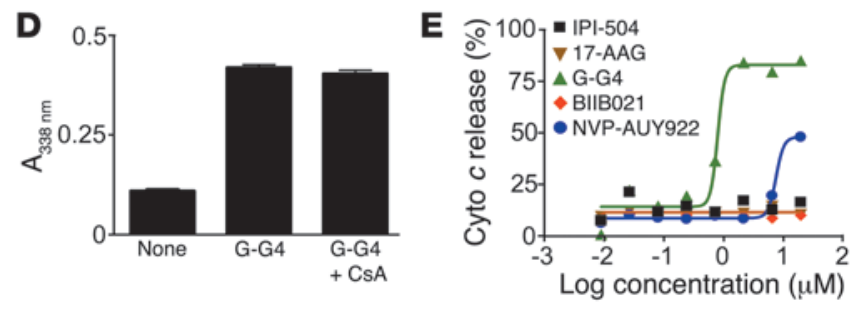

\section{Figure 3}

Mitochondrial dysfunction. (A) Mitochondrial membrane depolarization. Tetramethylrhodamine methyl ester-loaded (TMRM-loaded) HeLa cell mitochondria treated with Gamitrinibs or the various indicated agents $(1 \mu \mathrm{M})$ were analyzed for changes in fluorescence emission. (B) Analysis of individual mitochondriotropic moieties. TMRM-loaded HeLa cell mitochondria were incubated with 1.5 $\mu$ M 17-AAG plus tetraguanidinium (TG-OH) or Gamitrinib-G4 (left panel) or $0.7 \mu \mathrm{M}$ GA plus TPP-OH or Gamitrinib-TPP-OH (right panel) and analyzed for changes in fluorescence emission in the presence or absence of CsA $(5 \mu \mathrm{M})$. Arrows indicate point of addition. (C) Cytochrome $c$ (Cyto $c)$ release. Mitochondria isolated from HeLa cells treated with Gamitrinibs or 17-AAG (20 minutes) were analyzed for cytochrome $c$ release in supernatants (S) or pellets (P). Cox-IV or Ran was used as a mitochondrial or cytosolic marker, respectively. Reactivity of the antibody to Ran with isolated cytosolic extracts (C) was used as a control. (D) Mitochondrial accumulation. Isolated HeLa cell mitochondria were incubated with vehicle or Gamitrinib-G4 in the presence or absence of CsA and analyzed using absorbance. Data are the mean \pm SEM. (E) Analysis of nontargeted Hsp90 inhibitors. Isolated HeLa cell mitochondria were incubated with increasing concentrations of the various indicated agents for 3 hours and analyzed for cytochrome $c$ release. Data are representative of 2 independent experiments.

mitochondria. In these experiments, all Gamitrinibs induced rapid (20 minute) discharge of mitochondrial cytochrome $c$ in the supernatant, whereas unconjugated 17-AAG was ineffective (Figure 3C). Because Gamitrinib-induced loss of mitochondrial membrane potential was sensitive to CsA (Figure 3B), we next asked whether pharmacologic inhibition of CypD prevented the accumulation of the compound(s) in mitochondria. Gamitrinib-G4 readily accumulated in isolated tumor mitochondria, within the same time interval of induction of organelle permeability transition (Figure $3 \mathrm{D}$ ), in agreement with the data presented above (Figure 2, C-E). In these experiments, preincubation of isolated mitochondria with CsA, under the same conditions used to antagonize permeability transition (Figure 3B), did not reduce Gamitrinib accumulation in mitochondria (Figure 3D).

Additional derivatives of 17-AAG as well as purine- and isoxazole resorcinol-based Hsp90 antagonists (Supplemental Figure 2) have been recently developed, with promising anticancer activity in preclinical studies (25). Therefore, it was of interest to test whether these GA-modified or non-GA-based Hsp90 antagonists affected mitochondrial integrity. Gamitrinib-G4 induced sudden and complete discharge of cytochrome $c$ from tumor mitochondria (Figure $3 \mathrm{E})$, in agreement with the data above. In contrast, increasing concentrations of 17-AAG, hydroquinone derivative of 17-AAG (IPI504), purine analog (BIIB021), or isoxazole (NVP-AUY922) Hsp90 inhibitors (25) had no effect on cytochrome $c$ release (Figure 3E).

Induction of mitochondrial apoptosis by Gamitrinibs. A 3-hour exposure of lung adenocarcinoma H460 cells to Gamitrinib-G3 or -G4 was sufficient to produce concentration dependent $\left(\mathrm{IC}_{50} \sim 0.5 \mu \mathrm{M}\right)$ and complete loss of cell viability (Figure 4A, left panel) in the tumor cell population. Within this time frame, Gamitrinib-G1 or
17-AAG had no effect and Gamitrinib-G2 or Gamitrinib-TPP-OH had intermediate activity (Figure 4A, left panel). By 24 hours, all Gamitrinibs had comparably killed the entire tumor cell population, whereas 17-AAG had only partially reduced cell viability or cell proliferation (Figure 4A, right panel). As Gamitrinibs all comparably induce membrane depolarization of isolated mitochondria (Figure 3A), these data suggest that the Gamitrinib-G4 and -G3 moieties provide more efficient intracellular drug uptake, as compared with Gamitrinib-G1 and -G2 structures in vivo.

We next studied the cell death phenotype induced by Gamitrinibs. Treatment of $\mathrm{H} 460$ cells with Gamitrinib-G4 resulted in rapid loss of mitochondrial membrane potential in the whole tumor cell population, pronounced effector caspase activity, and cell death consistent with genuine mitochondrial apoptosis (Figure 4B). In contrast, vehicle alone had no effect on mitochondrial integrity or cell viability (Figure 4B). Proapoptotic Bcl-2 family proteins regulate mitochondrial cell death, in particular permeabilization of the outer membrane (21). Therefore, we next asked whether Gamitrinib-induced tumor cell killing was dependent on Bax, a multidomain proapoptotic Bcl-2 protein required for many cell death responses (31). In these experiments, Gamitrinib-G4 comparably induced concentration-dependent killing of wild-type or Bax ${ }^{-/}$colorectal cancer HCT116 cells (Figure 4C). Consistent with these data, Gamitrinib-G4 exhibited a broad spectrum of anticancer activity, and comparably killed a molecularly and genetically heterogeneous panel of tumor cell types, representative of epithelial and hematologic malignancies (Table 1). In contrast, exposure of these cells to the mitochondriotropic moiety (TG-OH) plus unconjugated 17-AAG had no effect on cell viability (Table 1). 

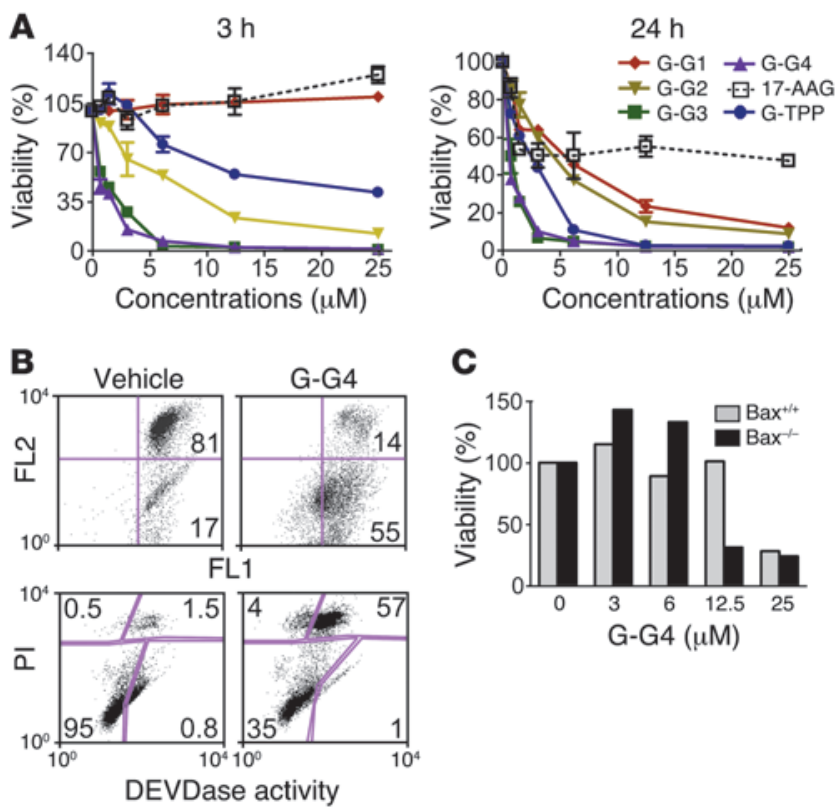

Mitochondriotoxic mechanism of action of Gamitrinibs. Current Hsp90 inhibitors predominantly cause cell cycle arrest in most tumor cell types, followed by a variable degree of apoptosis after a prolonged drug exposure of 48-72 hours. To test whether Gamitrinibs had a similar mechanism of action, we used breast adenocarcinoma SKBr3 cells, which are considered sensitive to Hsp90 inhibition. Gamitrinib-G4, Gamitrinib-TPP-OH, or unconjugated 17-AAG all resulted in comparable reduction of metabolic activity in SKBr3 cells by 48 hours and throughout a 96-hour interval after treatment (Figure 5A). However, most SKBr3 cells treated with 17-AAG were still alive after 72 hours, as shown using Trypan blue exclusion and light microscopy (Figure 5B). In contrast, Gamitrinibs were cytotoxic, and a 24-hour treatment was sufficient to cause nearly complete killing of the entire tumor cell population (Figure 5B). When analyzed in a model of long-term tumorigenicity, a brief (4-hour) exposure of H460 cells to Gamitrinib-G4 completely abolished colony formation in soft agar after a 2-week incubation (Figure 5C). In contrast, 17-AAG had no effect on tumorigenicity under the same conditions, and vehicle alone did not decrease H460 colony formation in soft agar (Figure 5C).

A hallmark of Hsp90 inhibition by conventional small molecule antagonists is the degradation of client proteins in the cytosol, with concomitant upregulation of $\mathrm{Hsp} 70$ chaperone levels. Consistent with this, treatment of cervical carcinoma HeLa cells with 17-AAG resulted in efficient loss of Hsp90 client proteins, Akt and Chk1 (14), and increased expression of Hsp70 (32), as analyzed by Western blotting (Figure 5D). At variance with this phenotype, incubation of HeLa cells with Gamitrinib-G4 had no effect on the levels of Hsp90 client proteins in the cytosol and did not result in upregulation of Hsp70 levels (Figure 5D).

Previous studies have shown that mitochondrial Hsp90 chaperones physically associate with the permeability pore component, CypD (21), and prevent its opening by a protein folding mechanism that antagonizes the initiation of cell death. Consistent with this model, siRNA silenc-

\section{Figure 4}

Gamitrinib-mediated anticancer activity. (A) Time course. H460 cells treated with the indicated concentrations of Gamitrinibs or 17-AAG were analyzed by a 3-(4,5-dimethylthiazol-2-yl)-2,5-diphenyltetrazolium bromide (MTT) assay after 3 hours (left panel) or 24 hours (right panel). Data are the mean $\pm \operatorname{SD}(n=2)$. (B) Caspase-associated cell death. $\mathrm{H} 460$ cells, treated with Gamitrinib-G4 or vehicle for 4 hours, were labeled with $\mathrm{JC}-1$ and analyzed for loss of mitochondrial membrane potential by changes in FL2/FL1 fluorescence ratio (top panel) or Asp-Glu-Val-Asp-ase (DEVDase) (caspase) activity (bottom panel) using multiparametric flow cytometry. The percentage of cells in each quadrant is indicated. PI, propidium iodide. (C) Insensitivity to Bax. Wild-type or $\mathrm{Bax}^{-/-} \mathrm{HCT} 116$ cells were incubated with the indicated increasing concentrations of Gamitrinib-G4 and analyzed after 6 hours using MTT assay. Data are representative of 2 experiments. ing of CypD in $\mathrm{H} 460$ cells (Figure 5E, inset) markedly attenuated Gamitrinib-G4-induced tumor cell killing (Figure 5E). In contrast, a nontargeted siRNA was without effect (Figure 5E, inset) and 17-AAG did not reduce $\mathrm{H} 460$ cell viability within the same time interval in the presence or absence of CypD (Figure 5E). Collectively, these data demonstrate that Gamitrinibs exhibit what we believe to be a unique, mitochondriotoxic mechanism of action, which involves CypD induction of organelle permeability transition, without affecting global Hsp90 homeostasis outside of mitochondria.

Selectivity of Gamitrinib anticancer activity. Because mitochondria of most normal tissues do not contain Hsp90 chaperones, it was
Table 1

Broad spectrum of Gamitrinib-G4 anticancer activity

\begin{tabular}{lccc} 
Cell line & \multicolumn{1}{c}{ Origin } & $\begin{array}{c}\text { Gamitrinib-G4 } \\
\text { IC }_{50}(\mu \text { M) }\end{array}$ & $\begin{array}{c}\text { 17-AAG/ } \\
\text { TG-0H IC }\end{array}$ \\
A431 & Squamous cell carcinoma & 4.0 & 26.8 \\
MDA-MB-231 & Breast adenocarcinoma (ER $\left.{ }^{-}\right)$ & 17.0 & 40.4 \\
U87MG & Glioblastoma multiformis & 12.4 & $>200.0$ \\
MCF-7 & Breast adenocarcinoma (ER $\left.{ }^{+}\right)$ & 15.2 & 103.4 \\
H1975 & Lung adenocarcinoma & 14.2 & $>200.0$ \\
DU145 & Prostate adenocarcinoma & 12.5 & $>200.0$ \\
H460 & Lung adenocarcinoma & 8.2 & $>200.0$ \\
HCT116 & Colorectal adenocarcinoma & 19.0 & $>200.0$ \\
K562 & Chronic myelogenous leukemia & 7.5 & 81.2 \\
& in blast crisis & & \\
HL60 & Myeloblastic leukemia & 9.2 & $>200.0$ \\
THP-1 & Monoblastic leukemia & 8.2 & $>200.0$ \\
Raji & B cell lymphoma & 3.1 & $>200.0$ \\
Mean & & $10.9 \pm 1.4$ & N.D. \\
& & & \\
\hline
\end{tabular}

The indicated tumor cell lines were incubated with increasing concentrations of Gamitrinib-G4 or unconjugated 17-AAG plus tetraguanidinium (TG-OH) mitochondriotropic moiety $(0-25 \mu \mathrm{M})$ and analyzed after 6 hours using MTT assay. Data are representative of 2 experiments. The indicated $\mathrm{IC}_{50}(\mu \mathrm{M})$ values refer to the concentrations of Gamitrinib-G4 that produce $50 \%$ tumor cell killing. ER, estrogen receptor. N.D., not determined. 

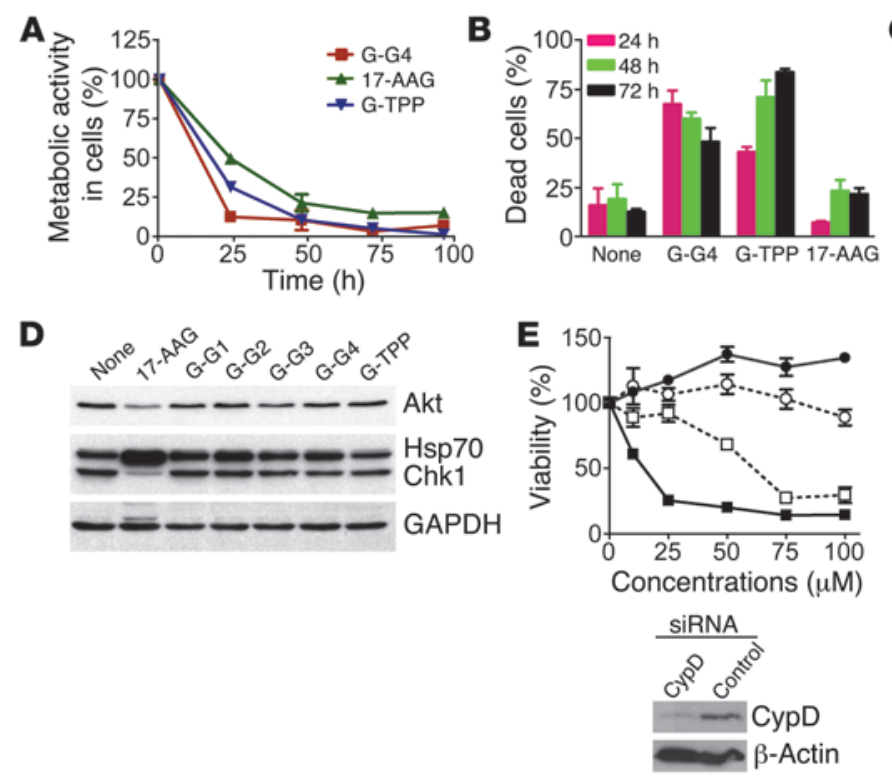

\section{Figure 5}

Gamitrinibs induction of mitochondrial apoptosis. (A) Comparison with 17-AAG. SKBr3 cells were treated with Gamitrinibs or 17-AAG $(10 \mu \mathrm{M})$ for the indicated time intervals and analyzed using MTT assay. Data are representative of at least 2 independent experiments. (B) Tumor cell killing. SKBr3 cells treated with vehicle, Gamitrinib-G4, Gamitrinib-TPP-OH, or 17-AAG (10 $\mu \mathrm{M})$, for the indicated time intervals, were analyzed by Trypan blue exclusion. Data are the mean \pm SEM $(n=3)$. (C) Colony formation. H460 cells treated with vehicle, 17-AAG $(50 \mu \mathrm{M})$, or Gamitrinib-G4 (50 $\mu \mathrm{M})$ for 4 hours were analyzed for colony formation in soft agar after 2 weeks. Representative microscopy fields are shown. Original magnification, $\times 40$. (D) Client protein modulation. HeLa cells treated with the indicated Gamitrinibs, 17-AAG $(5 \mu \mathrm{M})$, or vehicle were analyzed for modulation of Hsp90 client proteins Akt and Chk1 in the cytosol or changes in expression of Hsp70 after 24 hours by Western blotting. (E) Requirement for CypD in Gamitrinib anticancer activity. H460 cells transfected with control (closed symbols) or CypD (open symbols) siRNA were treated with 17-AAG (circles) or Gamitrinib-G4 (squares) and analyzed using MTT assay after 6 hours. Data are the mean $\pm \operatorname{SEM}(n=3)$. The inset shows Western blotting of CypD knockdown by siRNA.

of interest to test whether Gamitrinibs were selective anticancer agents. Exposure of normal mitochondria isolated from WS-1 human fibroblasts to Gamitrinib-G4 or $17-\mathrm{AAG}$ induced only a modest decrease in mitochondrial membrane potential in the presence or absence of CsA (Figure 6A). Similarly, Gamitrinibs did not induce discharge of cytochrome $c$ from normal mitochondria (Figure 6B). As control, mitochondria isolated from HeLa cells were nearly completely depleted of cytochrome $c$ after treatment with Gamitrinib-G1 but not 17-AAG (Figure 6B). Validating the specificity of these results, Gamitrinib-G4 readily accumulated in isolated normal mouse liver mitochondria, and this response was also unaffected by CypD inhibition with CsA (Figure 6C). Similar to the phenotype observed with tumor mitochondria, nontargeted 17-AAG did not accumulate in normal mitochondria (Figure 6C).

Consistent with this inability to induce mitochondrial permeability transition in normal cells, concentrations of Gamitrinib that readily killed tumor cell types did not cause cell death of normal primary cell types, including bovine aortic endothelial cells or intestinal epithelial cells, and only modestly reduced the viability of normal human foreskin fibroblasts or human umbilical vein endothelial cells (Figure 6D). Similarly, comparable concentrations of 17-AAG had no effect on the viability of the various normal human cells tested (Figure 6D).

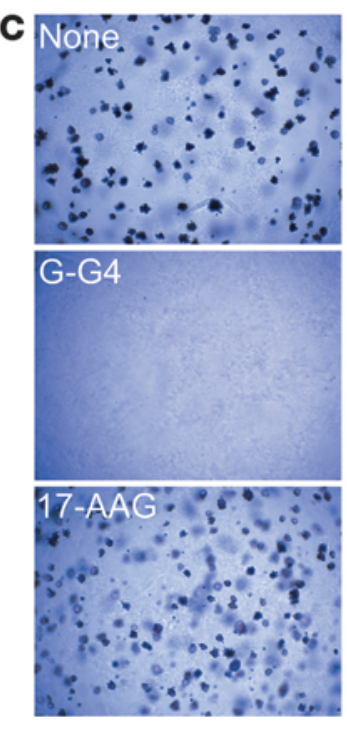

Gamitrinib inhibition of tumor growth in vivo. Systemic administration of Gamitrinib-G4 to mice inhibited the growth of established human leukemia (Supplemental Figure $3 \mathrm{~A}$ ), breast (Supplemental Figure $3 \mathrm{~B})$, and lung (Figure 7A) xenograft tumors in vivo. In contrast, comparable concentrations of 17-AAG had no effect on human lung cancer growth in mice (Figure 7A, top panel). Gamitrinibs carrying different mitochondriotropic moieties, i.e., Gamitrinib-G1 or -TPP-OH, also comparably inhibited lung cancer growth in vivo (Figure 7A, bottom panel). Tumors harvested from Gamitrinib-treated animals exhibited extensive apoptosis in situ (Figure 7B) and discharge of cytochrome $c$ in the cytosol (Figure 7C), suggestive of treatment-related mitochondrial dysfunction in vivo. At the concentrations used, the various Gamitrinibs did not cause significant animal weight loss throughout the treatment (Figure 7D). For preliminary toxicology experiments, organs, including brain, small and large intestine, heart, spleen, liver, pancreas, stomach, lung and kidneys, were collected from mice in the various treatment groups and analyzed histologically. In these studies, organs harvested from Gamitrinib-treated animals were histologically unremarkable compared with the vehicle group, with no changes in general architecture and no evidence of inflammation or liver steatosis (Supplemental Figure 4).

\section{Discussion}

In this study, we reported the combinatorial structure and activity of Gamitrinibs, which we believe to be the first class of small molecules engineered to selectively target a compartmentalized Hsp90 network in tumor mitochondria (22). Gamitrinibs efficiently accumulate in mitochondria, trigger sudden and irreversible organelle permeability transition, and induce exceedingly fast ( $\sim 1$ hour) and complete tumor cell killing by apoptosis. In turn this results in inhibition of tumor growth in vivo, with no detectable toxicity for normal cells or tissues. Differently from current Hsp90 antagonists, Gamitrinibs exhibit what we believe to be a novel mechanism of action, exclusively centered on induction of mitochondrial dysfunction, i.e., mitochondriotoxic, and do not affect global Hsp90 homeostasis outside of mitochondria. For these combined properties, we believe Gamitrinibs are novel, attractive anticancer agents, suitable for human testing.

New strategies for cancer drug discovery are urgently needed to remedy the high cost, low yield, and high risk of failure of traditional, target-centric drug discovery (7). An integrated, pathwayoriented approach that aims at cancer networks in their globality, 

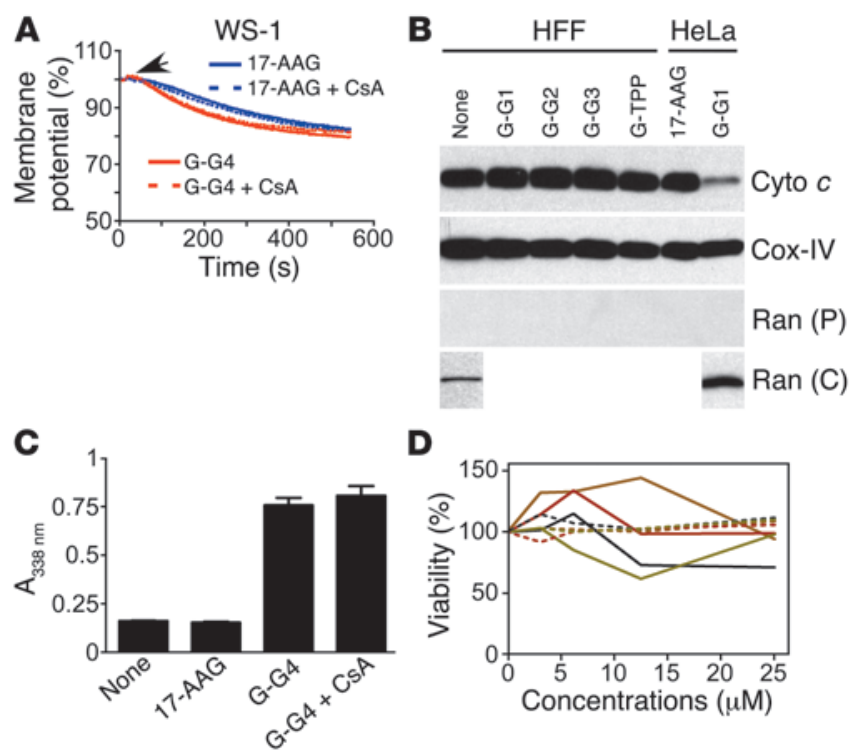

D

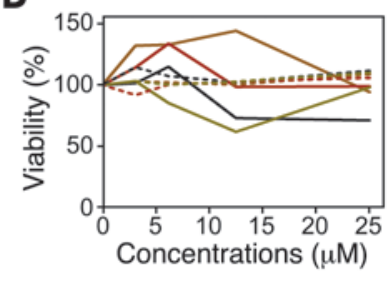

\section{Figure 6}

Selectivity of Gamitrinib anticancer activity. (A) Mitochondrial membrane potential. TMRM-loaded mitochondria isolated from WS-1 normal human fibroblasts were incubated with Gamitrinib-G4 or 17-AAG plus the uncoupled mitochondriotropic moiety $\mathrm{TG}-\mathrm{OH}$ and analyzed for changes in inner membrane potential in the presence or absence of CsA. (B) Cytochrome $c$ release. Mitochondria isolated from normal HFF fibroblasts were treated with Gamitrinibs or 17-AAG and analyzed by Western blotting. HeLa cells were used as control. Cox-IV or Ran was used as a mitochondrial or cytosolic marker, respectively. Reactivity of the antibody to Ran with isolated cytosolic extracts from HeLa or HFF cells was used as a control. (C) Mitochondrial accumulation. Isolated normal mouse liver mitochondria were incubated with vehicle, 17-AAG, or Gamitrinib-G4 in the presence or absence of CsA and analyzed using absorbance. Data are the mean \pm SEM. (D) Analysis of cell viability. Human fibroblasts (HFF, black line), bovine aortic endothelial cells (brown line), intestinal epithelial cells (red line), or human umbilical vein endothelial cells (green line) were treated with Gamitrinib-G4 (solid lines) or 17-AAG (dashed lines) and analyzed using MTT assay after 24 hours. Data are representative of 2 experiments. instead of individual genes in isolation (5), has recently emerged as a potentially attractive alternative to drug discovery (11). However, this may still not be sufficient to capture the complexity of cancer networks, as these pathways are not randomly assembled in tumor cells but compartmentalized in specialized, semiautonomous microenvironments (33). The data presented here, based on the combinatorial delivery of a well-known Hsp90 inhibitory moiety (17-AAG) (14) to a specialized compartment (mitochondria) (22), demonstrate that incorporating subcellular targeting in drug design is not only feasible but also leads to the generation of effective agents with specificities and mechanisms of action, which we believe to be novel.

Similar to the mitochondriotropic design of Gamitrinibs, the idea of manipulating mitochondrial homeostasis (21) for novel cancer therapeutics has been aggressively pursued (34). Small molecule modifiers of pro- or antiapoptotic $\mathrm{Bcl}-2$ family proteins that shift the balance in mitochondrial outer membrane permeability and trigger the release of apoptogenic proteins in the cytosol (35) have now reached the clinic (34). However, Gamitrinibs are different from these agents, as they directly target a potential upstream step in mitochondrial permeability transition, resulting in immediate depolarization of the inner membrane and sudden collapse of organelle integrity. Because this pathway is unaffected by proapoptotic regulators of outer membrane permeability, e.g., Bax (35), Gamitrinibs may be less sensitive to mechanisms conferring resistance to $\mathrm{Bcl}-2$ modifier drugs (34), including upregulation of antiapoptotic Mcl-1 (36) or activation of parallel pathways of cytochrome $c$ release (37).

The molecular requirements of mitochondrial permeability transition as a pathophysiological antecedent of apoptotic cell death have not been completely elucidated (21). Molecules that had long been held as essential constituents of a permeability transition pore, including the voltage-dependent anion channel (VDAC) (38) or the adenine nucleotide translocator (ANT) (39), turned out to be dispensable for mitochondrial cell death. Conversely, there is agreement that the matrix immunophilin CypD is essential to execute mitochondrial permeability transition, especially in response to certain cell death stimuli, for instance, $\mathrm{Ca}^{2+}$ overload or oxidative stress (40-42). Here, Gamitrinib-induced anticancer activity was dependent on CypD function, with respect to both depolarization of the inner membrane and tumor cell killing. Whether this reflects a role of $\mathrm{CypD}$ in an organized permeability transition pore (21) or its dynamic assembly in clusters of unfolded mitochondrial proteins that mediate conductance across the mitochondrial membrane (43) remains to be determined. However, the latter model better explains a cytoprotective function of mitochondrial Hsp90 chaperones (22), which may involve refolding of unfolded protein clusters generated by oxidative stress, with suppression of CypD-dependent pore opening (43). In this context, inhibition of mitochondrial chaperone activity by Gamitrinibs would acutely remove this steady-state cytoprotective mechanism, unrestraining an organelle unfolded protein response that culminates with CypD-dependent permeability transition and irreversible mitochondrial collapse (43). Although this cell death pathway has the hallmarks of mitochondrial apoptosis, it was only minimally affected by pharmacologic caspase inhibitors (data not shown), thus suggesting that Gamitrinib anticancer activity may also escape compensatory mechanisms downstream of mitochondria, typically involving upregulation of inhibitor of apoptosis (IAP) proteins (44).

Several small molecule Hsp90 antagonists based on the structure of GA (17-AAG, IPI-504) or purine or resorcinol (BIIB021, NVPAUY922) have been recently developed (25). As shown here, none of these agents, even at high concentrations, affected mitochondrial integrity, as quantified by analysis of mitochondrial inner membrane potential or cytochrome $c$ release. This likely reflects their inability to cross the mitochondrial membrane(s) or accumulate in the organelle, which was anticipated in earlier fluorescence localization studies with FITC-coupled 17-AAG (22). In the absence of mitochondrial targeting, the different $\mathrm{Hsp} 90$ antagonists primarily induce a cytostatic phenotype in tumor cells $(45,46)$, characterized by $\mathrm{G}_{1}$ and/or $\mathrm{G}_{2} / \mathrm{M}$ cell cycle arrest. This is due to loss of proliferation-associated Hsp90 client proteins in the cytosol (14) and a variable, but always partial degree of apoptosis after protracted drug exposure. Cell-type specific differences in the sensitivity to GA- or non-GA-based Hsp90 antagonists have also been 
A
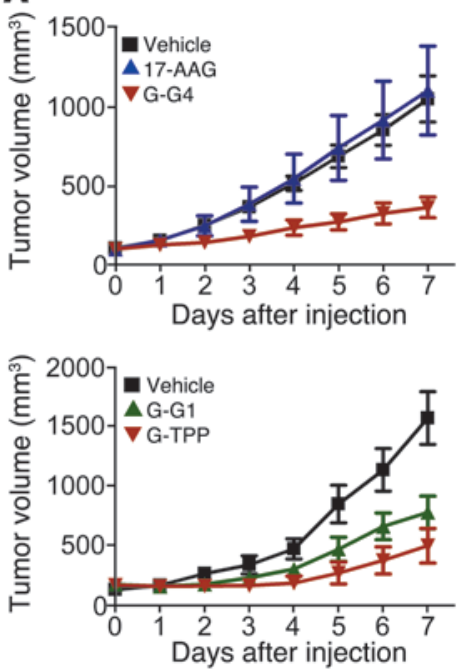

B

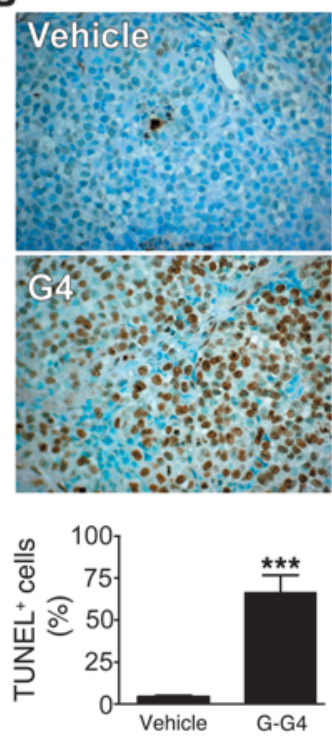

C

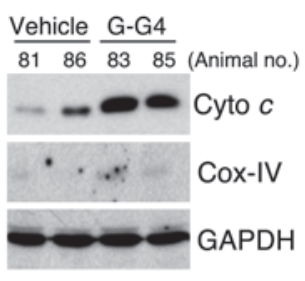

D

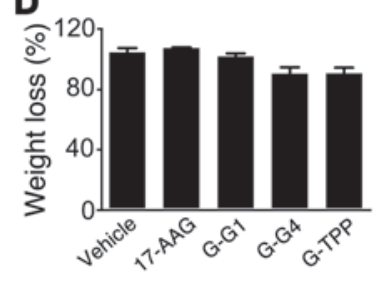

Figure 7

Gamitrinibs anticancer activity in vivo. (A) Kinetics of xenograft tumor growth. SCID/beige mice carrying $\mathrm{H} 460$ lung adenocarcinoma xenograft tumors $\left(100-150 \mathrm{~mm}^{3}\right)$ were treated with Gamitrinib-G4 or 17-AAG (top panel), with a dose escalation regimen as described in Supplemental Data, or with Gamitrinib-G1 or Gamitrinib-TPP-OH (bottom panel). Tumor volume was measured with a caliper. (B) Induction of apoptosis in vivo. Tumor specimens from vehicle- or Gamitrinib-treated tumors were analyzed for internucleosomal DNA fragmentation in situ (using TUNEL staining), and positive cells were quantified (bottom panel). Original magnification, $\times 400 .{ }^{* \star \star} P<0.0001$. Data are the mean \pm SEM (A and B). (C) Mitochondrial dysfunction in vivo. Cytosolic fractions from $\mathrm{H} 460$ xenograft tumors harvested from vehicle- or Gamitrinib-G4-treated animals were analyzed by Western blotting. Two mice per group were tested and the animal number is shown. (D) Animal weight. Mice treated with the various Gamitrinibs, 17-AAG, or vehicle were analyzed for percentage weight change at the end of the experiment. Data are the mean \pm SEM.

reported that may further affect their anticancer activity $(45,46)$. Conversely, mitochondrial targeting radically changed the activity profile of these agents, e.g., 17-AAG, as Gamitrinibs exclusively exhibited a cytotoxic phenotype, induced nearly complete tumor cell killing within 1 hour of treatment, and showed comparable efficacy against a broad spectrum of tumor cell types, regardless of molecular or genetic makeup. Further reinforcing their unique mechanism of action, Gamitrinibs did not affect the homeostatic functions of Hsp90 in the cytosol, leaving untouched the levels of various client proteins, without upregulation of Hsp70 expression. These observations reaffirm the selectivity of Gamitrinibs solely for the mitochondrial pool of Hsp90 (22) and suggest that this pathway may be unaffected by a third tier of compensatory mechanisms that are invariably induced by nontargeted Hsp90 inhibitors, including upregulation of cell survival molecules, for instance, Hsp70 (47), activation of oncogenic kinases (48), and paradoxical enhanced metastatic dissemination in vivo (49).

The mechanism of action of Gamitrinibs is also distinct from that of the peptidomimetic Shepherdin (50), which also inhibits Hsp90 ATPase activity and accumulates in mitochondria (22). Modeled on the binding interface between Hsp90 and the client protein, survivin (50), Shepherdin produces a dual phenotype of degradation of Hsp90 client proteins in the cytosol (50) as well as induction of mitochondrial permeability transition (22). These data suggest that the cytosolic transfer of Shepherdin may be of a cytoprotective mechanism ideally suited to favor cellular adaptation to noxious environments, in particular high levels of oxidative stress, which is invariably associated with tumor growth. Consistent with this model, mitochondrial TRAP-1 (20) has been recently implicated in protection from apoptosis induced by oxidative stimuli $(51,52)$. Although mitochondrial chaperones have been detected in certain normal tissues, for example, brain and testis, in which enhanced cytoprotection may be required for normal homeostasis, their affinity for ATPase pocket antagonists is likely 100-fold lower than that of tumor-associated Hsp90, thus adding to a potentially favorable therapeutic window of Gamitrinibs (53).

In summary, we have developed what we believe to be a novel, combinatorial drug design for the delivery of pathway inhibitors, i.e., Hsp90 ATPase antagonists (14), to specialized subcellular compartments. This drug engineering paradigm is cost-effective, amenable to further chemical optimization, and broadly applicable to structurally unrelated Hsp90 antagonists (25) and mitochondriotropic moieties. Although applied to the Hsp90 network, a similar approach could be also envisioned to selectively target other compartmentalized cancer networks (33). Functionally, the first products of this combinatorial approach, i.e., Gamitrinibs, exhibited radically different properties compared with their parental, nontargeted Hsp90 inhibitors, with respect to specificity, profile of anticancer activity, and mechanism of action. Therefore, such compartmentalized, pathway-oriented drug discovery can unlock novel properties 
of existing agents $(3,6)$, with promising preclinical activity, while limiting costly and low-yield new drug screenings (5).

\section{Methods}

Reagents. Complete Mini EDTA-free protease inhibitor cocktail was from Roche. 17-AAG was purchased from LC Laboratories. CsA was obtained from Sigma-Aldrich. Antibodies to cytochrome $c$ (Clontech), Cox-IV (Clontech), CypD (peptidylprolyl isomerase F, PPIF; Calbiochem), Chk1 (Santa Cruz Biotechnology Inc.), Ran (Novus Biologicals), Hsp70 (AbCam), Akt (Cell Signaling Technology Inc.), $\beta$-actin (Sigma-Aldrich), and GAPDH (Advanced ImmunoChemical Inc.) were used. siRNA oligonucleotides to CypD or control nontargeted siRNA were obtained from Dharmacon and were characterized previously (22).

Cell lines. Human chronic myelogenous leukemia in blast crisis K562, B lymphoblastoid Raji, monocytic leukemia THP-1, myeloblastic leukemia HL-60, breast adenocarcinoma MDA-MB-231 (ER-negative) or MCF-7 (ER-positive), lung adenocarcinoma $\mathrm{H} 460$ and $\mathrm{H} 1975$, prostate adenocarcinoma DU145, glioblastoma U87MG, colon adenocarcinoma HCT-116, and cervical carcinoma HeLa cells were obtained from ATCC and were maintained in culture according to the supplier's specifications. The normal human cell types, foreskin fibroblast HFF, epithelial fibroblast WS-1, and intestinal epithelial INT were also obtained from ATCC. Bovine aortic endothelial cells and human umbilical vein endothelial cells were isolated and maintained in culture according to published protocols (54).

Isolation of mitochondria and mitochondriotropic property of drugs. Mitochondria were isolated from HeLa cells as described previously (22). Briefly, HeLa cells were harvested and washed with TD buffer $(135 \mathrm{mM} \mathrm{NaCl}, 5 \mathrm{mM} \mathrm{KCl}$, $25 \mathrm{mM}$ Tris, $\mathrm{pH}$ 7.6). The cell pellet was suspended in 1 volume of CaRSB buffer $\left(10 \mathrm{mM} \mathrm{NaCl}, 1.5 \mathrm{mM} \mathrm{CaCl}_{2}, 10 \mathrm{mM}\right.$ Tris, $\mathrm{pH} 7.5$, protease inhibitor) and incubated for 5 minutes at $0^{\circ} \mathrm{C}$. Swelled cells were homogenized in a Dounce grinder and immediately mixed with 1.5 volume of MS buffer (210 mM mannitol, $70 \mathrm{mM}$ sucrose, $5 \mathrm{mM}$ Tris, pH 7.6, $5 \mathrm{mM}$ EDTA). Nuclei and other cellular debris were removed by centrifugation at $600 \times g$ for 15 minutes. Samples were further incubated with $200 \mu \mathrm{M}$ Gamitrinib or $17-\mathrm{AAG}$ per $2,600 \mu \mathrm{g}$ mitochondria for 5 minutes at $0^{\circ} \mathrm{C}$, and treated mitochondria were reisolated by centrifugation at $6,000 \times g$ for 10 minutes. The mitochondrial pellet was suspended in MS buffer and applied onto a $1 \mathrm{M} / 1.5 \mathrm{M}$ sucrose step gradient in $10 \mathrm{mM}$ Tris, $5 \mathrm{mM}$ EDTA, pH 7.6, $2 \mathrm{mM}$ DTT, plus protease inhibitors for 1.5 hours of centrifugation at $110,000 \times \mathrm{g}$. The mitochondrial bands were isolated, washed in MS buffer, and lysed in buffer containing $150 \mathrm{mM} \mathrm{NaCl}, 10 \mathrm{mM}$ Tris, $\mathrm{pH}$ 7.4, 0.5\% IGEPAL CA-630, 1 mM EDTA, plus protease inhibitors. Protein concentrations were determined using a Bio-Rad protein assay reagent with BSA as a standard. Absorbance on comparable protein concentrations was determined at 338 nm, using a DU530 spectrophotometer (Beckman Coulter). Due to maximum absorption and signals comparable to those obtained for 17-AAG and Gamitrinibs, absorbance at $338 \mathrm{~nm}$ was used for drug detection.

Mitochondrial function. For all in vitro experiments, all Gamitrinibs and 17-AAG were fully dissolved in DMSO. Normal or tumor mitochondria $(100 \mu \mathrm{g})$ were loaded with $0.1 \mathrm{mM}$ tetramethylrhodamine methyl ester (TMRM), incubated with Gamitrinibs or 17-AAG, with or without CsA, and analyzed continuously for changes in inner membrane potential at $549 \mathrm{~nm}$ excitation and $575 \mathrm{~nm}$ emission (Photon Technology International Inc.). The fluorescence intensity after treatment with $2 \mathrm{mM} \mathrm{CaCl}_{2}$ corresponded to a fully depolarized state. Alternatively, $\mathrm{H} 460$ cells were labeled with the fluorescent dye JC-1 (Molecular Probes) and analyzed for changes in red/green fluorescence (FL2/FL1) ratio after treatment with the various agents, using multiparametric flow cytometry. Cytochrome $c$ content in pellets or supernatants of drug-treated isolated mitochondria was determined by Western blotting.
Analysis of Hsp90 function. For GA affinity bead competition experiments, $\mathrm{SkBr} 3$ breast cancer cells were lysed in TNESV lysis buffer $(50 \mathrm{mM}$ Tris$\mathrm{HCl}, \mathrm{pH}$ 7.4, 1\% Nonidet P-40, 2 mM EDTA, 100 mM NaCl, 1 mM sodium orthovanadate, $1 \mathrm{mM}$ phenylmethylsulfonyl fluoride, $20 \mu \mathrm{g}$ of aprotinin and leupeptin per $\mathrm{ml}$ ). After centrifugation to clarify the supernatant, lysates were incubated with $0.00,0.50,1.00$, or $10.00 \mu \mathrm{M}$ Gamitrinib or $0.00,0.05,0.10$, or $0.50 \mu \mathrm{M}$ GA on ice for 30 minutes. Lysates (equal protein amounts) were then subjected to GA affinity bead precipitation and blotted for Hsp90 as previously described (55). Hsp90-specific band densities were determined by scanning and image analysis. GA affinity beads were prepared as previously described (55). In other experiments, chaperone-dependent glutathione-S-transferase-Chk1 (GST-Chk1) reconstitution was determined as described previously (30). Briefly, each sample contained $0.7 \mu \mathrm{g}$ of resin-bound GST-Chk1 (residues 1-265), $1 \mu \mathrm{g}$ of purified human Hsp90 $\alpha$, and the following amounts of other purified chaperone proteins: $10 \mu \mathrm{g}$ Hsp70, $2 \mu \mathrm{g}$ Hdj1, $2 \mu \mathrm{g} \mathrm{p} 50^{\text {cdc37 }}, 0.06$ units CK2, and $2.5 \mu \mathrm{g} \mathrm{p} 60^{\mathrm{Hop}}$. Optical densities due to Chk1-dependent phosphorylation of Cdc25 in the presence and absence of Gamitrinib or 17-AAG were determined and plotted as fold activation compared to the sample in which chaperone proteins were not added. In some experiments, HeLa cells were treated with Gamitrinibs (Gamitrinib-G1-G4) or 17-AAG (5 $\mu \mathrm{M})$ for 24 hours and isolated extracts were analyzed for modulation of Akt or Hsp70 expression by Western blotting.

Analysis of cell death. Modulation of cell viability was determined using 3-(4,5-dimethylthiazol-2-yl)-2,5-diphenyltetrazolium bromide (MTT) assay (22). For determination of apoptosis, cells were analyzed for caspase activity (Asp-Glu-Val-Asp-ase [DEVDase] activity) and plasma membrane integrity (propidium iodide) with multiparametric flow cytometry using CaspaTag (Intergen) (22).

Xenograft tumor models. All experiments involving animals were approved by an Institutional Animal Care and Use Committee at the University of Massachusetts Medical School. HL60 $\left(10 \times 10^{6}\right)$ or H460 $\left(4 \times 10^{6}\right)$ cells suspended in sterile PBS $(200 \mu \mathrm{l})$ were injected subcutaneously into both flanks of 10-week-old CB17 SCID/beige (Taconic Farms) immunocompromised female mice. Alternatively, MDA-MB-231 cells $\left(5 \times 10^{6}\right)$, suspended in $200 \mu \mathrm{l}$ of $50 \%$ Matrigel (BD Biosciences), were used for subcutaneous injection in $\mathrm{CB} 17 \mathrm{SCID} /$ beige mice. When superficial tumors reached volumes of $100-150 \mathrm{~mm}^{3}$, animals were randomized in 2 groups (2 tumors/ mouse, 3 animals/group) and treated with vehicle (DMSO) or Gamitrinib dissolved in 20\% Cremophor EL (Sigma-Aldrich) in PBS by i.p. injection. Gamitrinib-G4 was injected i.p. with the following schedule: HL60 xenografts, $2 \mathrm{mg} / \mathrm{kg}$ twice daily; $\mathrm{H} 460$ xenografts, $2 \mathrm{mg} / \mathrm{kg}$ twice daily for day 0 , $2.5 \mathrm{mg} / \mathrm{kg}$ twice daily for day $1,3.0 \mathrm{mg} / \mathrm{kg}$ twice daily for the duration of treatment; MDA-MB-231 xenografts, $2 \mathrm{mg} / \mathrm{kg}$ twice daily for days $0-2$, $2.5 \mathrm{mg} / \mathrm{kg}$ twice daily for days $3-5$, and $3 \mathrm{mg} / \mathrm{kg}$ twice daily throughout the rest of the treatment. 17-AAG was dissolved in 20\% Cremophor EL and administered as systemic i.p. injections, with the same dose-escalating regimen as Gamitrinib-G4 in H460 xenograft studies. Gamitrinib-G1 was injected i.p. with following schedule: $30 \mathrm{mg} / \mathrm{kg}$ daily for days $0-2$ and 50 $\mathrm{mg} / \mathrm{kg}$ daily for the rest of treatment. Gamitrinib-TPP-OH was injected i.p. at $10 \mathrm{mg} / \mathrm{kg}$ daily throughout the duration of the experiment. Tumor measurements were taken daily with a caliper, and tumor volume was calculated with the formula ([length in millimeters $\left.] \times[\text { width in millimeters }]^{2}\right) / 2$. Mice in the various treatment groups were weighed at the beginning and at the end of each experiment.

In vivo subcellular fractionation. HL60 xenograft tumors from vehicle- or Gamitrinib-treated mice were harvested when they reached a volume of $300-400 \mathrm{~mm}^{3}$, and cytosol fractions were prepared using a Mitochondria Isolation Kit (Sigma-Aldrich). Cytochrome $c$ released in the cytosol was analyzed by Western blotting. 
In situ internucleosomal DNA fragmentation as shown by TUNEL staining. At the end of treatment, tumors were harvested from vehicle- or Gamitrinibtreated animals, fixed in formalin, embedded in paraffin, and sectioned. TUNEL staining was performed with the ApopTag Plus Peroxidase In situ Apoptosis Detection Kit (Chemicon), according to the instruction manual, as described previously (56). Images were captured using an Olympus microscope with an on-line charge-coupled device camera at $\times 400$ magnification (necrotic regions were excluded from the analysis). For quantification, TUNEL-positive cells were counted in 10 independent areas of a $\times 400$ magnification field (10 fields/each group).

Histology. Animals in the vehicle or Gamitrinib group were euthanized at the end of the experiment, and organs, including brain, colon, heart, kidney, liver, lung, pancreas, small intestine, spleen, and stomach, were collected, fixed in formalin, and embedded in paraffin. Sections $(5 \mu \mathrm{m})$ were put on high-adhesive slides, stained with $\mathrm{H} \& \mathrm{E}$, and analyzed by light microscopy.

Statistics. Data were analyzed using the unpaired Student's $t$ test on a GraphPad software program (Prism 4.0). All of the statistical tests were 2 sided. A $P$ value of 0.05 was considered to be statistically significant.

\section{Acknowledgments}

We thank Kris Depew and Nafeeza Hafeez (Infinity Pharmaceuticals Inc.) for technical assistance, M. DeFeudis for generous support, and D. Garlick for histologic evaluation. This work was supported by National Institutes of Health grants CA78810, CA90917, and HL54131 (D.C. Altieri) and by funding from the Intramural Research Program of the National Cancer Institute, National Institutes of Health (K. Beebe, B. Scroggins, and L. Neckers).

Received for publication September 30, 2008, and accepted in revised form January 7, 2009.

Address correspondence to: Dario C. Altieri, Department of Cancer Biology, LRB428, University of Massachusetts Medical School, 364 Plantation Street, Worcester, Massachusetts 01605, USA. Phone: (508) 856-5775; Fax: (508) 856-5792; E-mail: dario. altieri@umassmed.edu.
1. Vogelstein, B., and Kinzler, K.W. 2004. Cancer genes and the pathways they control. Nat. Med. 10:789-799.

2. Sawyers, C. 2004. Targeted cancer therapy. Nature. 432:294-297.

3. Strausberg, R.L., Simpson, A.J., Old, L.J., and Riggins, G.J. 2004. Oncogenomics and the development of new cancer therapies. Nature. 429:469-474.

4. Deininger, M., Buchdunger, E., and Druker, B.J. 2005. The development of imatinib as a therapeutic agent for chronic myeloid leukemia. Blood. 105:2640-2653.

5. van der Greef, J., and McBurney, R.N. 2005. Innovation: Rescuing drug discovery: in vivo systems pathology and systems pharmacology. Nat. Rev. Drug Discov. 4:961-967.

6. Butcher, E.C. 2005. Can cell systems biology rescue drug discovery? Nat. Rev. Drug Discov. 4:461-467.

7. Schein, P.S., and Scheffler, B. 2006. Barriers to efficient development of cancer therapeutics. Clin. Cancer Res. 12:3243-3248.

8. Sjoblom, T., et al. 2006. The consensus coding sequences of human breast and colorectal cancers. Science. 314:268-274.

9. Wood, L.D., et al. 2007. The genomic landscapes of human breast and colorectal cancers. Science. 318:1108-1113.

10. Araujo, R.P., and Liotta, L.A. 2006. A control theoretic paradigm for cell signaling networks: a simple complexity for a sensitive robustness. Curr. Opin. Chem. Biol. 10:81-87.

11. Rajasethupathy, P., Vayttaden, S.J., and Bhalla, U.S. 2005. Systems modeling: a pathway to drug discovery. Curr. Opin. Chem. Biol. 9:400-406.

12. Lamb, J. 2007. The Connectivity Map: a new tool for biomedical research. Nat Rev Cancer 7:54-60.

13. McClellan, A.J., et al. 2007. Diverse cellular functions of the Hsp90 molecular chaperone uncovered using systems approaches. Cell. 131:121-135.

14. Isaacs, J.S., Xu, W., and Neckers, L. 2003. Heat shock protein 90 as a molecular target for cancer therapeutics. Cancer Cell. 3:213-217.

15. Young, J.C., Moarefi, I., and Hartl, F.U. 2001. Hsp90: a specialized but essential protein-folding tool. J. Cell Biol. 154:267-273.

16. Pearl, L.H., and Prodromou, C. 2000. Structure and in vivo function of Hsp90. Curr. Opin. Struct. Biol. 10:46-51.

17. Freeman, B.C., and Yamamoto, K.R. 2002. Disassembly of transcriptional regulatory complexes by molecular chaperones. Science. 296:2232-2235.

18. Christianson, J.C., Shaler, T.A., Tyler, R.E., and Kopito, R.R. 2008. OS-9 and GRP94 deliver mutant alpha1-antitrypsin to the Hrd1-SEL1L ubiquitin ligase complex for ERAD. Nat. Cell Biol. 10:272-282.

19. Eustace, B.K., et al. 2004. Functional proteomic screens reveal an essential extracellular role for hsp90 alpha in cancer cell invasiveness. Nat. Cell Biol. 6:507-514.

20. Felts, S.J., et al. 2000. The hsp90-related protein TRAP1 is a mitochondrial protein with distinct functional properties. J. Biol. Chem. 275:3305-3312.

21. Green, D.R., and Kroemer, G. 2004. The pathophysiology of mitochondrial cell death. Science. 305:626-629.

22. Kang, B.H., et al. 2007. Regulation of tumor cell mitochondrial homeostasis by an organelle-specific Hsp90 chaperone network. Cell. 131:257-270.

23. Neckers, L., and Ivy, S.P. 2003. Heat shock protein 90. Curr. Opin. Oncol. 15:419-424.

24. Sausville, E.A., Tomaszewski, J.E., and Ivy, P. 2003. Clinical development of 17-allylamino, 17-demethoxygeldanamycin. Curr. Cancer Drug Targets. 3:377-383.

25. Solit, D.B., and Chiosis, G. 2008. Development and application of Hsp90 inhibitors. Drug Discov. Today. 13:38-43.

26. Drysdale, M.J., Brough, P.A., Massey, A., Jensen, M.R., and Schoepfer, J. 2006. Targeting Hsp90 for the treatment of cancer. Curr. Opin. Drug Discov. Devel. 9:483-495.

27. Fernandez-Carneado, J., et al. 2005. Highly efficient, nonpeptidic oligoguanidinium vectors that selectively internalize into mitochondria. J. Am. Chem. Soc. 127:869-874.

28. Armstrong, J.S. 2007. Mitochondrial medicine: pharmacological targeting of mitochondria in disease. Br. J. Pharmacol. 151:1154-1165.

29. Stebbins, C.E., et al. 1997. Crystal structure of an Hsp90-geldanamycin complex: targeting of a protein chaperone by an antitumor agent. Cell. 89:239-250.

30. Arlander, S.J., et al. 2006. Chaperoning checkpoint kinase 1 (Chk1), an Hsp90 client, with purified chaperones. J. Biol. Chem. 281:2989-2998.

31. Wei, M.C., et al. 2001. Proapoptotic BAX and BAK: a requisite gateway to mitochondrial dysfunction and death. Science. 292:727-730.

32. Beere, H.M., et al. 2000. Heat-shock protein 70 inhibits apoptosis by preventing recruitment of procaspase-9 to the Apaf-1 apoptosome. Nat. Cell Biol. 2:469-475.

33. Philips, M.R. 2005. Compartmentalized signalling of Ras. Biochem. Soc. Trans. 33:657-661.

34. Fesik, S.W. 2005. Promoting apoptosis as a strategy for cancer drug discovery. Nat. Rev. Cancer. 5:876-885

35. Bouchier-Hayes, L., Lartigue, L., and Newmeyer, D.D. 2005. Mitochondria: pharmacological manip- ulation of cell death. J. Clin. Invest. 115:2640-2647.

36. Konopleva, M., et al. 2006. Mechanisms of apoptosis sensitivity and resistance to the $\mathrm{BH} 3$ mimetic ABT-737 in acute myeloid leukemia. Cancer Cell. 10:375-388.

37. Mizuta, T., Shimizu, S., Matsuoka, Y., Nakagawa, T., and Tsujimoto, Y. 2007. A Bax/Bak-independent Mechanism of Cytochrome c Release. J. Biol. Chem. 282:16623-16630.

38. Baines, C.P., Kaiser, R.A., Sheiko, T., Craigen, W.J., and Molkentin, J.D. 2007. Voltage-dependent anion channels are dispensable for mitochondrial-dependent cell death. Nat. Cell Biol. 9:550-555.

39. Kokoszka, J.E., et al. 2004. The ADP/ATP translocator is not essential for the mitochondrial permeability transition pore. Nature. 427:461-465.

40. Baines, C.P., et al. 2005. Loss of cyclophilin D reveals a critical role for mitochondrial permeability transition in cell death. Nature. 434:658-662.

41. Nakagawa, T., et al. 2005. Cyclophilin D-dependent mitochondrial permeability transition regulates some necrotic but not apoptotic cell death. Nature. 434:652-658.

42. Schinzel, A.C., et al. 2005. Cyclophilin D is a component of mitochondrial permeability transition and mediates neuronal cell death after focal cerebral ischemia. Proc. Natl. Acad. Sci. U. S. A. 102:12005-12010.

43. He, L., and Lemasters, J.J. 2002. Regulated and unregulated mitochondrial permeability transition pores: a new paradigm of pore structure and function? FEBS Lett. 512:1-7.

44. Wright, C.W., and Duckett, C.S. 2005. Reawakening the cellular death program in neoplasia through the therapeutic blockade of IAP function. J. Clin. Invest. 115:2673-2678.

45. Hostein, I., Robertson, D., DiStefano, F., Workman, P., and Clarke, P.A. 2001. Inhibition of signal transduction by the Hsp90 inhibitor 17-allylamino-17-demethoxygeldanamycin results in cytostasis and apoptosis. Cancer Res. 61:4003-4009.

46. Eccles, S.A., et al. 2008. NVP-AUY922: A novel heat shock protein 90 inhibitor active against xenograft tumor growth, angiogenesis, and metastasis. Cancer Res. 68:2850-2860.

47. Guo, F., et al. 2005. Mechanistic role of heat shock protein 70 in Bcr-Abl-mediated resistance to apoptosis in human acute leukemia cells. Blood. 105:1246-1255.

48. Koga, F., et al. 2006. Hsp90 inhibition transiently activates Src kinase and promotes Src-dependent Akt and Erk activation. Proc. Natl. Acad. Sci. U. S. A. 103:11318-11322.

49. Price, J.T., et al. 2005. The heat shock protein 90 
research article

inhibitor, 17-allylamino-17-demethoxygeldanamycin, enhances osteoclast formation and potentiates bone metastasis of a human breast cancer cell line. Cancer Res. 65:4929-4938.

50. Plescia, J., et al. 2005. Rational design of shepherdin, a novel anticancer agent. Cancer Cell. 7:457-468.

51. Hua, G., Zhang, Q., and Fan, Z. 2007. Heat shock protein 75 (TRAP1) antagonizes reactive oxygen species generation and protects cells from granzyme M-mediated apoptosis. J. Biol. Chem.
282:20553-20560.

52. Pridgeon, J.W., Olzmann, J.A., Chin, L.S., and Li, L. 2007. PINK1 protects against oxidative stress by phosphorylating mitochondrial chaperone TRAP1. PLoS Biol. 5:e172.

53. Kamal, A., et al. 2003. A high-affinity conformation of Hsp90 confers tumour selectivity on Hsp90 inhibitors. Nature. 425:407-410.

54. Blanc-Brude, O.P., et al. 2003. Therapeutic targeting of the survivin pathway in cancer: initiation of mitochondrial apoptosis and suppression of tumor-associated angiogenesis. Clin. Cancer Res. 9:2683-2692.

55. Marcu, M.G., Schulte, T.W., and Neckers, L. 2000. Novobiocin and related coumarins and depletion of heat shock protein 90-dependent signaling proteins. J. Natl. Cancer Inst. 92:242-248.

56. Dohi, T., Xia, F., and Altieri, D.C. 2007. Compartmentalized phosphorylation of IAP by protein kinase A regulates cytoprotection. Mol. Cell. 27:17-28. 